\title{
Seasonal differences in leaf-level physiology give lianas a competitive advantage over trees in a tropical seasonal forest
}

\author{
Zhi-Quan Cai $\cdot$ Stefan A. Schnitzer $\cdot$ Frans Bongers
}

Received: 16 April 2008 / Accepted: 13 April 2009 / Published online: 6 May 2009

(C) The Author(s) 2009. This article is published with open access at Springerlink.com

\begin{abstract}
Lianas are an important component of most tropical forests, where they vary in abundance from high in seasonal forests to low in aseasonal forests. We tested the hypothesis that the physiological ability of lianas to fix carbon (and thus grow) during seasonal drought may confer a distinct advantage in seasonal tropical forests, which may explain pan-tropical liana distributions. We compared a range of leaf-level physiological attributes of 18 co-occurring liana and 16 tree species during the wet and dry seasons in a tropical seasonal forest in Xishuangbanna, China. We found that, during the wet season, lianas had significantly higher $\mathrm{CO}_{2}$ assimilation per unit mass $\left(A_{\text {mass }}\right)$, nitrogen concentration $\left(N_{\text {mass }}\right)$, and $\delta^{13} \mathrm{C}$ values, and lower leaf mass per unit area (LMA) than trees, indicating that lianas have higher assimilation rates per unit leaf mass and higher integrated water-use efficiency (WUE), but lower leaf
\end{abstract}

Communicated by Carlos Ballaré.

Z.-Q. Cai

Xishuangbanna Tropical Botanical Garden,

The Chinese Academy of Sciences, 666303 Mengla, China

S. A. Schnitzer $(\square)$

Department of Biological Sciences, University of Wisconsin-Milwaukee,

PO Box 413, Milwaukee, WI 53201, USA

e-mail: schnitzer@uwm.edu

S. A. Schnitzer

Smithsonian Tropical Research Institute,

Apartado, 0843-03092 Balboa, Republic of Panama

Z.-Q. Cai - F. Bongers

Forest Ecology and Forest Management Group,

Centre for Ecosystem Studies, Wageningen University,

Wageningen, The Netherlands structural investments. Seasonal variation in $\mathrm{CO}_{2}$ assimilation per unit area $\left(A_{\text {area }}\right)$, phosphorus concentration per unit mass $\left(P_{\text {mass }}\right)$, and photosynthetic N-use efficiency (PNUE), however, was significantly lower in lianas than in trees. For instance, mean tree $A_{\text {area }}$ decreased by $30.1 \%$ from wet to dry season, compared with only $12.8 \%$ for lianas. In contrast, from the wet to dry season mean liana $\delta^{13} \mathrm{C}$ increased four times more than tree $\delta^{13} \mathrm{C}$, with no reduction in PNUE, whereas trees had a significant reduction in PNUE. Lianas had higher $A_{\text {mass }}$ than trees throughout the year, regardless of season. Collectively, our findings indicate that lianas fix more carbon and use water and nitrogen more efficiently than trees, particularly during seasonal drought, which may confer a competitive advantage to lianas during the dry season, and thus may explain their high relative abundance in seasonal tropical forests.

Keywords Liana distribution · Nitrogen-use efficiency · Tropical forest physiology $\cdot$ Water-use efficiency

\section{Introduction}

Annual rainfall and the seasonal distribution of rainfall are arguably two of the most important factors responsible for the distribution of plant species within the tropics (Gentry 1982). While some tropical forests have high annual rainfall with relatively little change in the amount of monthly precipitation during the year (e.g., rain forests), most tropical forests experience seasonal drought, where precipitation is greatly reduced for up to 6 months per year (Walsh and Newbery 1999). During periods of seasonal drought, plants may be exposed to considerable water stress, indicated by low leaf water potentials and wilting (Veenendaal et al. 1995), as well as increased mortality and substantially 
decreased growth rates (Condit et al. 1995; Engelbrecht et al. 2005). Consequently, many plant species in seasonal tropical forests have special adaptations to deal with periods of drought, such as reduced net assimilation rate, reduced stomatal conductance, or deciduousness (Holbrook et al. 1995; Borchert 1998; Slot and Poorter 2007). The presence of one or more of these adaptations may determine the abundance and distribution of a species or functional group in a particular forest (Swaine 1996; Bongers et al. 1999; Schnitzer 2005; Domingues et al. 2007).

Most organisms increase in abundance with increasing mean annual precipitation and decreasing seasonality (Gentry 1982). One plant group that is an exception to this general rule, however, are the lianas (woody vines), which appear to increase in abundance with decreasing mean annual precipitation and increasing seasonality (Schnitzer 2005; DeWalt et al., unpublished; but see van der Heijden et al. 2008). Schnitzer (2005) proposed that lianas exhibit their distinct geographic distribution due to their unique ability to grow during seasonal drought, while their competitors, particularly trees, have greatly reduced physiological activity. This dry season growth advantage may allow lianas to increase in abundance in seasonal forests, whereas the competitive advantage is absent in aseasonal forests, thus explaining pan-tropical patterns of liana abundance (Schnitzer 2005). Lianas are a key component of many tropical forests, where they can influence a number of important forest processes, including tree recruitment, regeneration, fecundity, and mortality (Putz and Mooney 1991; Schnitzer and Bongers 2002; Schnitzer et al. 2000, 2004, 2005; Wright et al. 2005; Kainer et al. 2006). Thus, explaining the mechanisms responsible for the abundance of lianas in tropical forests is critical for understanding tropical forest dynamics, as well as predicting how liana abundance will change with climate and land-use changes.

Currently, the evidence to support the dry season growth advantage hypothesis is limited. For example, in the seasonally deciduous forest of Barro Colorado Island in Panama (BCI), Schnitzer (2005) measured the height growth of liana and tree species throughout consecutive wet and dry seasons and reported that, during the wet season, lianas grew two times faster than trees, but in the dry season this growth difference increased to seven times, suggesting that lianas benefit during the dry season relative to trees, possibly because lianas suffer less water stress during seasonal drought. This finding is consistent with observations that many liana species retain and even produce new leaves during severe seasonal droughts, whereas most trees do not (Putz and Windsor 1987; Opler et al. 1991; Kalácska et al. 2005). Several characteristics common to lianas may enable them to compete particularly well during seasonal droughts, including: deep and well developed root systems (Tyree and Ewers 1996; Restom and Nepstad 2004), hydraulic activity (Andrade et al. 2005), low leaf construction costs per unit photosynthetic area (Castellanos 1991), and rapid vegetative growth rates (Putz 1984; Schnitzer et al. 2000, 2004), as well as high potential for response to changes in light intensity (Avalos and Mulkey 1999; Salzer et al. 2006) and elevated atmospheric $\mathrm{CO}_{2}$ concentrations (Granados and Korner 2002; Mohan et al. 2006; Zotz et al. 2006). To date, however, there have been no systematic tests of the dry season growth advantage hypothesis to explain patterns of liana distribution.

In this study, we compared seasonal variability in leaf physiology among co-occurring liana and tree species throughout wet and dry seasons in a tropical seasonal forest in Xishuangbanna, SW China, to determine whether lianas, compared to trees, can fix more carbon, and thus grow more, during seasonal drought (Schnitzer 2005). We predicted that lianas should perform better than trees during the dry season via higher carbon fixation and resource use efficiency. During the wet season, however, lianas and trees should be more similar to each other in each of these attributes.

\section{Materials and methods}

Study site

The study was conducted in a tropical seasonal forest in Xishuangbanna $\left(21^{\circ} 09^{\prime}-22^{\circ} 33^{\prime} \mathrm{N}, 99^{\circ} 58^{\prime}-101^{\circ} 50^{\prime} \mathrm{E}\right)$, SW China. The forest of Xishuangbanna is on the northern edge of tropical SE Asia, and it differs from lowland rain forests located close to the equator mostly by having fewer epiphytes and megaphanerophytes. Liana abundance and diversity in this region, however, is relatively high, especially in seasonal forests (Cai et al. 2009), which is the most common and dominant forest type of the region (Zhu et al. 2006).

Lying in the East Asian Monsoon Region, Xishuangbanna is dominated by warm-wet air masses from the Indian Ocean in summer and continental air masses from the sub-tropical regions in winter, resulting in a highly seasonal environment. The forest used in this study receives approximately $1,550 \mathrm{~mm}$ of rainfall annually, of which $85 \%$ occurs in the 6-month rainy season (MayOctober). During the study period, rainfall varied from $3 \mathrm{~mm}$ in February 2004 to $297 \mathrm{~mm}$ in August 2004. Mean monthly temperature in this area is $21.4^{\circ} \mathrm{C}$ and ranges from 14.5 to $25.7^{\circ} \mathrm{C}$ (Fig. 1a). Surface soil $(0-20 \mathrm{~cm}$ ) was drier in the dry season compared to the wet season, while deep soil water content $(100 \mathrm{~cm})$ was similar (Fig. 1b). 
Fig. 1 Seasonal changes in monthly rainfall and average air temperature (a) and volumetric water content (b) in 2004 (open circle dry season in March, black circle wet season in September). Weather data was from the nearby Meteorological Station of Xishuangbanna

Tropical Botanical Garden, The Chinese Academy of Sciences

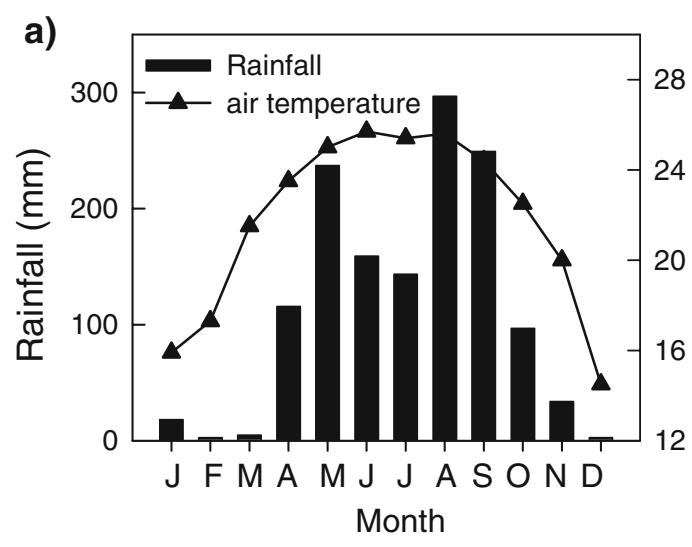

b)

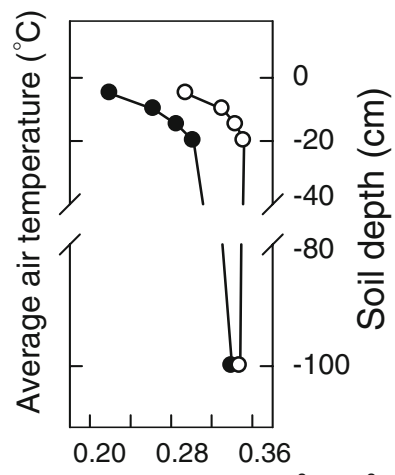

Soil water content $\left(\mathrm{cm}^{3} \mathrm{~cm}^{-3}\right)$
Study species and measurements

We studied 18 evergreen liana species and 16 evergreen tree species (all species utilize $\mathrm{C}_{3}$ photosynthesis; Table 1). To determine photosynthetic parameters, including photosynthetic rate and dark respiration, we collected branches from the upper canopy using a tree pruner attached to a long handle. For each tree and liana species, we sampled 4 6 leaves from the same individual (2-3 individuals per species) at the end of each season. We use leaf functional trait measurements because leaves provide valuable insights into whole-plant performance (Wright et al. 2004a, b; Poorter and Bongers 2006). All individuals had comparable stem diameters (dbh) and were growing in the same general area on similar soil types. The trees were approximately $20 \mathrm{~m}$ tall, and the branches and leaves of the liana species were located on top of the tree crowns. All branches were collected during the wet (September) and dry (MarchApril) seasons between 9:30 and 11:00 a.m., when maximum photosynthetic rates occurred (Foster and Brooks 2005; Domingues et al. 2007). Within 10 min of collection, we cut the branches under water, immersed the stems in deionized water to maintain the xylem water column, and measured photosynthesis. Photosynthetic parameters were measured on fully expanded, recently matured sun canopy leaves (methods follow Foster and Brooks 2005; Salzer et al. 2006; Santiago and Wright 2007). We measured the rate of $\mathrm{CO}_{2}$ assimilation per unit area $\left(A_{\text {area }}\right)$ under a lightsaturating irradiance (Photon flux density $>1,500 \mu \mathrm{mol}$ $\mathrm{m}^{-2} \mathrm{~s}^{-1}$, provided by an internal red/blue LED light source; LI6400-02B) under ambient $\mathrm{CO}_{2}$ concentration ( $\left.2380 \mathrm{ppm}\right)$ with a portable photosynthetic system (Li-6400; LiCor, Lincoln, NE, USA). Leaf temperature and vapor pressure deficit (VPD) in the cuvette were kept at $25-26^{\circ} \mathrm{C}$ and less than $1 \mathrm{kPa}$, respectively. We also measured dark respiration $\left(R_{\mathrm{d}}\right)$ in the leaf chamber, allowing several minutes for the leaves to stabilize before recording data.

Following field measurements, we immediately placed each leaf (excluding the petiole) in a sealed plastic bag containing a damp paper towel. In the laboratory, we extracted the chlorophyll and total carotenoid contents from the leaves with $80 \%(\mathrm{v} / \mathrm{v})$ acetone in the dark and measured pigments (Lichtenthaler and Wellburn 1983) with a spectrophotometer (UV-B 2501; Shimadzu, Japan). We measured the area of each leaf with a leaf area meter (Li3000A; Li-Cor). We then oven-dried the leaves at a minimum of $48 \mathrm{~h}$ at $70^{\circ} \mathrm{C}$ and calculated leaf dry mass and leaf mass area (LMA, $\mathrm{g} \mathrm{cm}^{-2}$ ). For each plant, we ground three to five leaves into a fine powder for elemental analyses in the Biogeochemical Laboratory of the Kunming Division of the Xishuangbanna Tropical Botanical Garden, The Chinese Academy of Sciences. The total $\mathrm{N}$ concentration per unit leaf dry mass $\left(N_{\text {mass }}, \%\right)$ was determined using semimicro Kjeldahl, a commonly used wet digestion procedure. Phosphorus concentration $\left(P_{\text {mass }}, \mathrm{mg} \mathrm{g}^{-1}\right)$ was measured by atomic absorption spectrum-photometry (AAS, Type 932GBC; Scientific Equipment, Australia). Instantaneous photosynthetic nitrogen- and phosphorus-use efficiency (PNUE, $\mu \mathrm{molC} \mathrm{mol}{ }^{-1} \mathrm{~N} \mathrm{~s}^{-1}$; PPUE, mmolC mol ${ }^{-1} \mathrm{P} \mathrm{s}^{-1}$ ) were calculated as $\mathrm{CO}_{2}$ assimilation rate per unit mass ( $\left.A_{\text {mass }}\right)$ per leaf $N_{\text {mass }}$ and $P_{\text {mass }}$, respectively.

We measured the $\delta^{13} \mathrm{C}$ (in parts per thousand) of all species on $2 \mathrm{mg}$ ground subsamples of leaves using a Thermo Finnigan MAT stable isotope mass spectrometer (Bremen, Germany) at the Stable Isotope Laboratory in Institute of Botany, The Chinese Academy of Sciences. $\delta^{13} \mathrm{C}$ provides an integrated estimate of the ratio of photosynthesis to conductance, and therefore can be used as an index of intrinsic water-use efficiency (Farquhar and Richards 1984). Because we collected young (but fully expanded) leaves near the end of the wet and dry seasons, and because leaf development and expansion occurs rapidly in tropical forests (Kursar and Coley 1991), our $\delta^{13} \mathrm{C}$ measurements likely reflect the season in which they were taken.

\section{Statistical analysis}

We used two-way repeated-measures ANOVA to compare morphological and physiological leaf traits between growth-form (liana and tree), season (wet and dry) and 
Table 1 Leaf traits of evergreen liana and tree species measured during the wet season in a seasonal forest in Xishuangbanna, China

\begin{tabular}{|c|c|c|c|c|c|c|c|c|c|c|c|c|c|c|c|}
\hline Species & amily & LA & LMA & $A_{\text {area }}$ & $A_{\text {mass }}$ & $R_{\mathrm{d} \text { area }}$ & $R_{\mathrm{d} \text { mass }}$ & $A / R_{\mathrm{d}}$ & $N_{\text {mass }}$ & $P_{\text {mass }}$ & A/Chl & $\mathrm{Car} / \mathrm{Chl}$ & $\delta^{13} \mathrm{C}$ & PNUE & PPUE \\
\hline \multicolumn{16}{|l|}{ Liana species } \\
\hline Iodes covalis & Icacinaceae & 144.5 & 79.2 & 9.17 & 115.8 & 1.13 & 14.3 & 8.12 & 4.99 & 2.73 & 30.1 & 0.23 & -31.02 & 32.5 & 1.31 \\
\hline Fissistigma polyanthoides & Annonaceae & 77.5 & 69.8 & 11.45 & 164 & 1.67 & 23.9 & 6.86 & 4.19 & 2.38 & 46.5 & 0.18 & -29.08 & 54.8 & 2.13 \\
\hline Bauhinia glauca & Caesalpiniaceae & 15 & 55.8 & 6.62 & 118.6 & 0.67 & 12 & 9.87 & 2.43 & 1.76 & 33.4 & 0.22 & -30.57 & 68.3 & 2.09 \\
\hline Ziziphus attopensis & Rhamnaceae & 22.1 & 65.2 & 10.69 & 163.9 & 1.01 & 15.5 & 10.58 & 2.51 & 2.15 & 40.2 & 0.22 & -30.1 & 91.3 & 2.37 \\
\hline Gnetum parvifolium & Gnetaceae & 110.5 & 72.7 & 10.23 & 140.7 & 1.14 & 15.7 & 8.97 & 3.55 & 1.54 & 35.2 & 0.25 & -31.18 & 55.5 & 2.84 \\
\hline Tetrastigma planicaulum & Vitaceae & 58.5 & 72.8 & 11.45 & 157.2 & 1.34 & 18.4 & 8.54 & 2.65 & 1.97 & 61.6 & 0.23 & -29.02 & 83.2 & 2.47 \\
\hline Byttneria aspera & Sterculiaceae & 81.8 & 46 & 11.95 & 259.6 & 1.41 & 30.6 & 8.48 & 3.12 & 2.18 & 63.1 & 0.22 & -29.92 & 116.6 & 3.70 \\
\hline Uncaria macrophylla & ubiaceae & 101.4 & 111.1 & 9.08 & 81.7 & 0.78 & 7.0 & 11.64 & 2.13 & 1.31 & 30.8 & 0.28 & -30.09 & 53.7 & 1.93 \\
\hline Bauhinia yunnanensis & Caesalpiniaceae & 8.1 & 61.8 & 8.67 & 140.4 & 0.65 & 10.5 & 13.34 & 3.61 & 2.98 & 27.9 & 0.2 & - & 54.4 & 1.46 \\
\hline Tinomiscium tokinensis & Menispermaceae & 228 & 59.7 & 9.95 & 166.6 & 0.87 & 14.6 & 11.43 & 2.86 & 2.04 & 64.5 & 0.23 & -31.41 & 81.6 & 2.53 \\
\hline Ficus subulata & Moraceae & 71.1 & 68.7 & 7.72 & 112.3 & 0.56 & 8.2 & 13.78 & 2.54 & 1.46 & 27 & 0.23 & .64 & 61.9 & 2.38 \\
\hline Uncaria rhynchophylla & Rubiaceae & 42.8 & 115 & 8.46 & 73.5 & 0.82 & 7.1 & 10.31 & 1.47 & 0.82 & 25.6 & 0.24 & -28.96 & 70.3 & 2.79 \\
\hline Ventilago calyculata & Rhamnaceae & 47.8 & 63.3 & 10 & 158 & 1.14 & 18 & 8.77 & 3.17 & 1.46 & 36.6 & 0.23 & -30.24 & 69.7 & 3.35 \\
\hline Millettia dielsiana & Leguminosae & 41.1 & 63.6 & 10.45 & 164.3 & 1.65 & 25.9 & 6.33 & 3.37 & 1.23 & 29.1 & 0.21 & -29.46 & 68.2 & 4.14 \\
\hline Fissistigma polyanthum & Annonaceae & 28.5 & 55.9 & 10.4 & 186.1 & 1.11 & 19.9 & 9.37 & 2.3 & 1.26 & 32.1 & 0.2 & -31.49 & 113.4 & 4.57 \\
\hline Millettia oo & Leguminosae & 37 & 107.3 & 12.65 & 117.9 & 1.54 & 14.3 & 8.21 & 2.45 & 1.62 & 25 & 0.24 & -29 & 67.5 & 2.26 \\
\hline Celastr & Celastraceae & 33 & 92.6 & 11.13 & 120.1 & 1.5 & 16.2 & 7.42 & 2.25 & 2.07 & 52.1 & 0.24 & -28.65 & 74.8 & 1.80 \\
\hline Securidaca & Polygalaceae & 32.3 & 84.2 & 9.44 & 112.2 & 0.78 & 9.3 & 12.11 & 3.13 & 1.83 & 40.2 & 0.25 & -30.39 & 50.3 & 1.90 \\
\hline \multicolumn{16}{|l|}{ Tree species } \\
\hline Ficus cyrtophylla & Moraceae & 71.5 & 50.2 & 9.69 & 193.1 & 0.89 & 17.7 & 10.89 & 3.34 & 1.88 & 45.2 & 0.24 & -30.48 & 81 & 3.19 \\
\hline Combretum latifolium & Combretaceae & 135.9 & 134.6 & 12.12 & 90.1 & 1.76 & 13.1 & 6.89 & 1.65 & 1.04 & 24.1 & 0.23 & -29.09 & 76.2 & 2.68 \\
\hline Ficus hirta & Moraceae & 149.2 & 84 & 11.88 & 141.4 & 1.18 & 14 & 10.06 & 3.17 & 3.52 & 45.4 & 0.24 & -30.69 & 62.4 & 1.25 \\
\hline Baccaurea ramiflora & Euphorbiaceae & 116 & 88.1 & 9.87 & 112.1 & 1.06 & 12 & 9.31 & 1.95 & 1.42 & 38.3 & 0.22 & -32.12 & 80.7 & 2.45 \\
\hline Carallia lanceaefolia & Rhizophoraceae & 69.2 & 101.2 & 6.58 & 65 & 0.58 & 5.7 & 11.34 & 2.12 & 1.5 & 27.5 & 0.25 & -32.06 & 43 & 1.34 \\
\hline Ficus auriculata & Moraceae & 516.9 & 76.3 & 7.89 & 103.4 & 0.72 & 9.4 & 10.96 & 1.37 & 1.96 & 43.1 & 0.2 & -32.17 & 105.8 & 1.64 \\
\hline Lepisanthes senegalensis & Sapindaceae & 107.3 & 61.2 & 6.05 & 98.8 & 0.48 & 7.8 & 12.6 & 2.97 & 1.28 & 17.9 & 0.23 & -34.15 & 46.6 & 2.39 \\
\hline Barringtonia macrostachya & Lecythidaceae & 238.9 & 129 & 10.56 & 81.9 & 1.06 & 8.2 & 9.96 & 2.48 & 1.75 & 15.1 & 0.24 & -32.71 & 46.3 & 1.45 \\
\hline Shorea chinensis & Dipterocarpaceae & 92.7 & 73.3 & 9.07 & 123.7 & 0.96 & 13.1 & 9.45 & 2.32 & 1.62 & 25.6 & 0.24 & -33.72 & 74.6 & 2.37 \\
\hline Ficus callosa & Moraceae & 191.5 & 104.1 & 17.5 & 168.1 & 1.89 & 18.2 & 9.26 & 2.45 & 1.88 & 45.5 & 0.25 & -30.2 & 95.9 & 2.78 \\
\hline Castanopsis indica & Fagaceae & 136.9 & 95.5 & 11.34 & 118.8 & 1.65 & 17.3 & 6.87 & 2.14 & 1.21 & 33.1 & 0.21 & -31.31 & 77.9 & 3.04 \\
\hline Mayodendron igneum & Bignoniaceae & 36.8 & 78.6 & 8.08 & 102.8 & 0.82 & 10.4 & 9.85 & 2.7 & 1.59 & 21.7 & 0.24 & -29.39 & 53.3 & 2.00 \\
\hline Litsea panamonja & Lauraceae & 115.2 & 92.5 & 9.58 & 103.6 & 1.06 & 11.5 & 9.04 & 2.58 & 2.71 & 54.4 & 0.23 & -30.46 & 56.1 & 1.19 \\
\hline Leea crispa & Leeaceae & 98.1 & 123.3 & 7.76 & 62.9 & 0.85 & 6.9 & 9.13 & 3.36 & 2.28 & 16.1 & 0.23 & -30.72 & 26.2 & 0.86 \\
\hline Ficus superba & Moraceae & 115.2 & 81.5 & 10.32 & 126.7 & 1.07 & 13.1 & 9.64 & 2.62 & 1.62 & 33.5 & 0.22 & -31.15 & 67.8 & 2.43 \\
\hline Syzygium latilimbum & Myrtaceae & 147.4 & 115.5 & 11.65 & 100.9 & 1.65 & 14.3 & 7.06 & 1.21 & 0.87 & 41.8 & 0.24 & -28.87 & 116.9 & 3.58 \\
\hline Liana mean & & 65.6 & 74.7 & 9.97 & 141.8 & 1.10 & 15.63 & 9.67 & 2.93 & 1.82 & 38.94 & 0.23 & -30.07 & 70.4 & 2.6 \\
\hline Tree mean & & 146.2 & 93.1 & 10.00 & 112.1 & 1.11 & 12.04 & 9.52 & 2.40 & 1.76 & 33.02 & 0.23 & -31.21 & 69.4 & 2.2 \\
\hline
\end{tabular}

Nomenclature follows Li et al. 1996

Measurements and units: $L A$ leaf area $\left(\mathrm{cm}^{2}\right), L M A$ leaf mass ratio $\left(\mathrm{g} \mathrm{cm}^{-2}\right), A_{\text {area }}$ area-based $\mathrm{CO}_{2}$ assimilation $\left(\mathrm{mmol} \mathrm{m} \mathrm{m}^{-2} \mathrm{~s}^{-1}\right), A_{\text {mass }}$ mass-based CO 2 assimilation $\left(\mathrm{nmol} \mathrm{g} \mathrm{s}^{-1} \mathrm{~s}^{-1}\right), R_{\text {d area }}$ area-based dark respiration $\left(\mu \mathrm{mol} \mathrm{m} \mathrm{m}^{-2} \mathrm{~s}^{-1}\right), R_{\text {d mass }}$ mass-based dark respiration $\left(\mu \mathrm{mol} \mathrm{g}^{-1} \mathrm{~s}^{-1}\right), N_{\text {mass }}$ nitrogen per mass $(\%)$, $P_{\text {mass }}$ phosphorus per mass ( $\left.\mathrm{mg} \mathrm{g}^{-1}\right), A / C h l$ photosynthesis rate to chlorophyll ratio, Car/Chl cartenoid to chlorophyll ratio, $\delta^{13} C$ carbon isotope (\%o), PNUE photosynthetic N-use efficiency $\left(\mu \mathrm{molC} \mathrm{mol}^{-1} \mathrm{~N} \mathrm{~s}^{-1}\right), P P U E$ photosynthetic P-use efficiency (mmolC mol ${ }^{-1} \mathrm{P} \mathrm{s}^{-1}$ )

growth-form $\times$ season interactions. We then used LSD contrasts to examine whether each trait differed between growth-forms within and between the seasons. Data were tested for normality and homogeneity of variance and, when necessary, were $\log _{10}$-transformed before analysis. Rather than focus on a phylogenetically controlled sampling strategy (e.g., Cai et al. 2008), we intentionally selected species from multiple families in order to generalize as much as possible about lianas and trees. Because Ficus is a particularly speciose genus, with more than 40 species in Xishuangbanna (Xu 1994), we included five Ficus species in this study. To control for a potential phylogenetic bias, we used the average response of the five Ficus species (Schnitzer 2005). Because the results did not differ 
whether we used the mean of the Ficus species or all five Ficus species as replicates, we present the results from the larger dataset of 16 tree species (Table 1). Correlations amongst leaf traits were analyzed with a Pearson's correlation; all reported correlations were significant at an alpha level of $P<0.05$. All statistical analyses were conducted using SPSS version 11.0 (SPSS, Chicago, IL, USA).

\section{Results}

During the wet season, species' mean LMA varied from 46 to $134.6 \mathrm{~g} \mathrm{~m}^{-2}$, with the smallest value for the liana Byttneria aspera and the largest one for the tree Combretum latifolium. The rate of $\mathrm{CO}_{2}$ assimilation per unit area $\left(A_{\text {area }}\right)$ and unit mass $\left(A_{\text {mass }}\right)$ ranged from 6.05 to $17.5 \mu \mathrm{mol} \mathrm{m} \mathrm{m}^{-2} \mathrm{~s}^{-1}$ and from 65 to $259.6 \mathrm{nmol} \mathrm{g}^{-1} \mathrm{~s}^{-1}$ for the trees Lepianthes senegalensis and Ficus cyrtophylla, respectively (Table 1). The tree Syzygium latilimbum had the lowest $N_{\text {mass }}(1.21 \%)$ and the liana Iodes covalis had the highest (4.99\%). Variation in Car/Chl among the 34 species was small, while the differences in values of PNUE were quite large, ranging from 26.2 to $116.9 \mu \mathrm{molC}$ $\mathrm{mol}^{-1} \mathrm{~N} \mathrm{~s}^{-1}$. Water-use efficiency, measured by $\delta^{13} \mathrm{C}$, ranged from -28.65 to $-34.15 \%$.

During the wet season, lianas and trees had a similar mean $A_{\text {area }}, R_{\mathrm{d} \text { area }}, P_{\text {mass }}$, PNUE, PPUE, and Car/Chl ratio (Fig. 2). Compared to trees, however, lianas had significantly higher wet season $\delta^{13} \mathrm{C}, A_{\text {mass }}, N_{\text {mass }}$, and $A / C h l$ ratio, as well as significantly lower LMA and leaf area (Fig. 2).

Lianas and trees responded differently to seasonal drought, as indicated by significant growth-form by season interactions for $A_{\text {area }}, P_{\text {mass }}, \delta^{13} \mathrm{C}$ and PNUE (Table 2). For example, the similar $A_{\text {area }}$ of liana and tree species in the wet season was not maintained throughout the dry season, with tree $A_{\text {area }}$ becoming significantly lower than that of lianas (growth-form $\times$ season interaction, $F_{1,13}=8.08$, $P=0.01$; Fig. 2; Table 2). Although there was large variation in $A_{\text {area }}$ in the dry season $\left(4.56-12.53 \mu \mathrm{mol} \mathrm{m}^{-2} \mathrm{~s}^{-1}\right)$, mean liana $A_{\text {area }}$ remained relatively high $(8.7 \mu \mathrm{mol}$ $\mathrm{m}^{-2} \mathrm{~s}^{-1}, 87.2 \%$ of that of the wet season), whereas mean dry season tree $A_{\text {area }}$ declined to $60.9 \%$ of that of the wet season $\left(6.1 \mu \mathrm{mol} \mathrm{m}{ }^{-2} \mathrm{~s}^{-1}\right.$; Fig. 2). The rate of $\mathrm{CO}_{2}$ assimilation per unit mass $\left(A_{\text {mass }}\right)$ also decreased slightly more during the dry season for trees (77.5\% of the wet season) than for lianas $(81.8 \%$ of the wet season), although the growth-form by season interaction for $A_{\text {mass }}$ was not significant (Table 2). For tree species, both $P_{\text {mass }}$ and PNUE decreased significantly from wet to dry season $(P=0.048$ and $P=0.042$, respectively), whereas neither factor changed for lianas $(P=0.12$ and $P=0.23$, respectively), resulting in a significant growth-form $\times$ season interaction (Table 2; Fig. 2). $N_{\text {mass }}$ decreased significantly from wet to
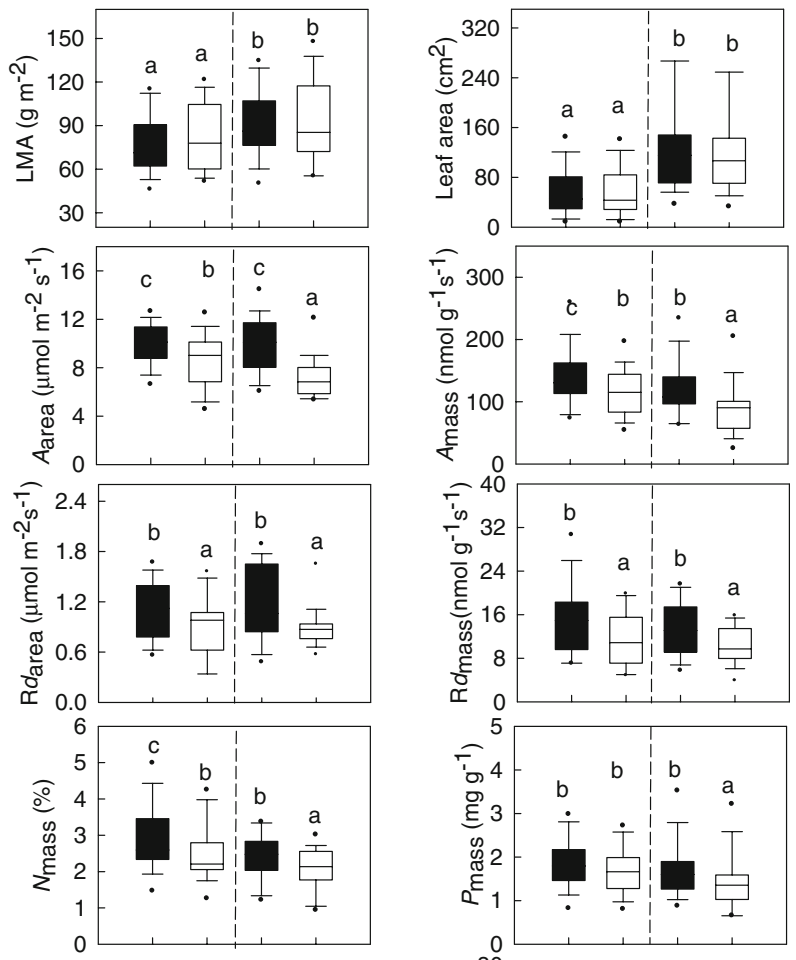

- 0
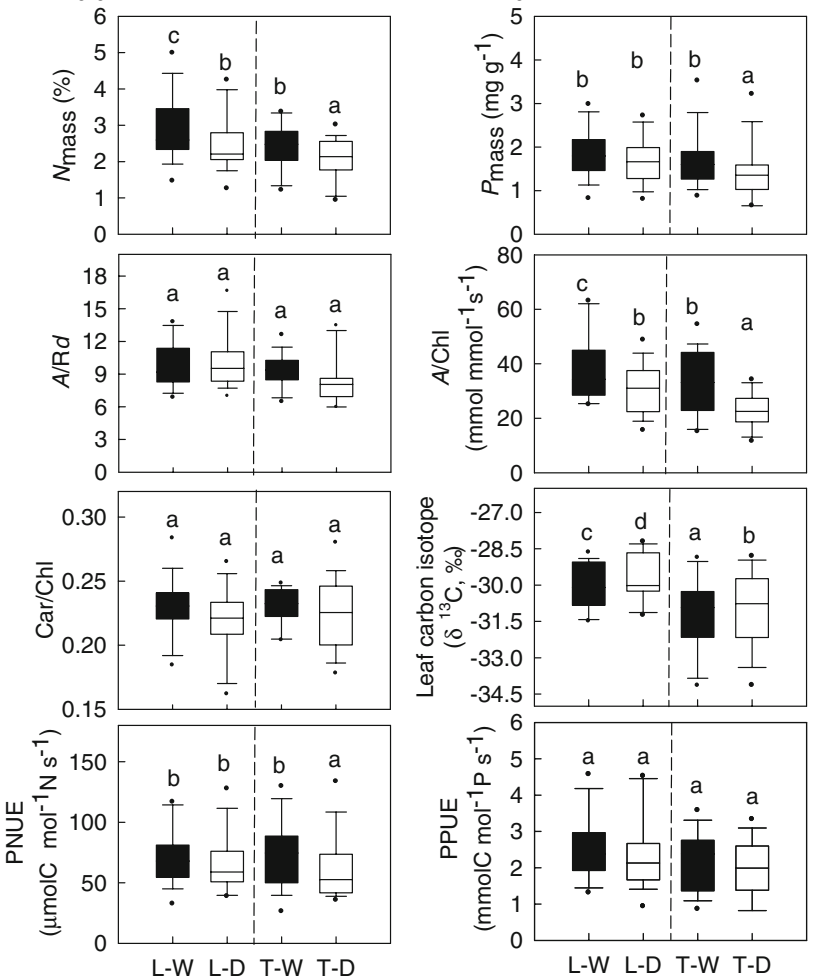

Fig. 2 Box plots of leaf attributes of woody species in the seasonal forest at Xishuangbanna, China. Liana and trees are represented by $L$ and $T$, and wet and dry seasons are represented by $-W$ and $-D$, respectively. Boxes indicate median, 25 th and 75 th percentile values, with error bars showed 10th and 90th percentile values, and solid circles indicating outliers. We compared growth-form, season, and the growth-form $\times$ season interaction using a repeated-measured ANOVA with post-hoc least significant difference contrasts to compare the mean leaf traits between the growth forms during each season and between the seasons for each growth form. Different letters indicate significant differences at $P \leq 0.05$. Trait abbreviations are defined in Table 1

dry season for trees $(P=0.000)$ and only marginally for lianas $(P=0.052)$, but the growth-form by season interaction was not significant (Table 2). The $\delta^{13} \mathrm{C}$ values of both 
Table 2 Two-way repeatedmeasures ANOVA comparing morphological and physiological leaf traits between growth-form (liana vs tree), season (wet vs dry), and the growth-form $\times$ season interaction

Bold $P$ values indicate significant differences

Numerator degrees of freedom $(d f)=1$ and denominator $d f=13$ for all response variables except $\delta^{13} \mathrm{C}$, LMA, and PPUE, which had denominator $d f=14$, and $\mathrm{Car} / \mathrm{Chl}$, which had a denominator $d f=17$

\begin{tabular}{|c|c|c|c|c|c|c|}
\hline \multirow{2}{*}{$\begin{array}{l}\text { Response } \\
\text { variable }\end{array}$} & \multicolumn{2}{|c|}{ Growth-form } & \multicolumn{2}{|l|}{ Season } & \multicolumn{2}{|c|}{ Growth-form $\times$ Season } \\
\hline & $F$-ratio & $P$ & $F$-ratio & $P$ & $F$-ratio & $P$ \\
\hline$A_{\text {area }}$ & 2.189 & 0.1630 & 70.795 & 0.000 & 8.079 & 0.0140 \\
\hline$A_{\text {mass }}$ & 6.809 & 0.022 & 40.760 & 0.000 & 0.202 & 0.660 \\
\hline$N_{\text {mass }}$ & 3.855 & 0.071 & 63.012 & 0.000 & 2.491 & 0.139 \\
\hline$P_{\text {mass }}$ & 0.548 & 0.472 & 189.224 & 0.000 & 10.544 & 0.006 \\
\hline$R_{\mathrm{d} \text { mass }}$ & 2.476 & 0.140 & 12.871 & 0.003 & 0.687 & 0.422 \\
\hline$R_{\mathrm{d} \text { area }}$ & 0.071 & 0.794 & 6.851 & 0.021 & 0.169 & 0.688 \\
\hline$A / R_{\mathrm{d}}$ & 3.642 & 0.079 & 0.733 & 0.407 & 3.071 & 0.103 \\
\hline A/Chl & 2.315 & 0.152 & 53.521 & 0.000 & 1.477 & 0.246 \\
\hline$\delta^{13} \mathrm{C}$ & 7.333 & 0.017 & 18.723 & 0.001 & 10.807 & 0.005 \\
\hline PNUE & 0.440 & 0.519 & 20.229 & 0.001 & 5.575 & 0.034 \\
\hline LMA & 5.106 & 0.040 & 2.337 & 0.149 & 1.797 & 0.201 \\
\hline Car/Chl & 0.424 & 0.524 & 1.160 & 0.297 & 0.024 & 0.879 \\
\hline PPUE & 1.633 & 0.222 & 7.708 & 0.015 & 1.044 & 0.324 \\
\hline LA & 6.518 & 0.024 & 2.645 & 0.128 & 3.904 & 0.070 \\
\hline
\end{tabular}

lianas and trees increased significantly from wet to dry season (lianas: $1.06 \% ; P=0.002$; trees: $0.25 \% ; P=0.009$ ), but the significant growth-form $\times$ season interaction indicated that $\delta^{13} \mathrm{C}$ increased significantly more during the dry season for lianas than for trees (Table 2). Collectively, these results support the hypothesis that lianas fix more carbon and use water and nitrogen more efficiently than trees during seasonal drought.

Leaf mass area (LMA) was strongly negatively correlated with $A_{\text {mass }}$ for lianas and trees during the wet season (Fig. 3a), but only for lianas during the dry season (Fig. 3b). This finding suggests that, compared to trees, lianas realized relatively high carbon assimilation at low leaf construction cost, particularly during the dry season. Water-use efficiency (WUE, indicated by $\delta^{13} \mathrm{C}$ values) was significantly negatively correlated with PNUE in both wet and dry seasons for trees, but not for lianas (Fig. 4). Thus, lianas appear to maintain relatively high PNUE even in periods of high WUE, whereas trees do not.

\section{Discussion}

Testing the dry season growth advantage hypothesis

Our findings demonstrate that, compared to trees, lianas fixed more carbon per unit leaf area and exhibited less water stress during the dry season relative to the wet season. The ability to fix carbon during the dry season when trees are less active may give lianas a competitive advantage over trees in seasonal forests, which may help explain their high abundance in seasonal dry forests and lower abundance in aseasonal wet forests (Schnitzer 2005;
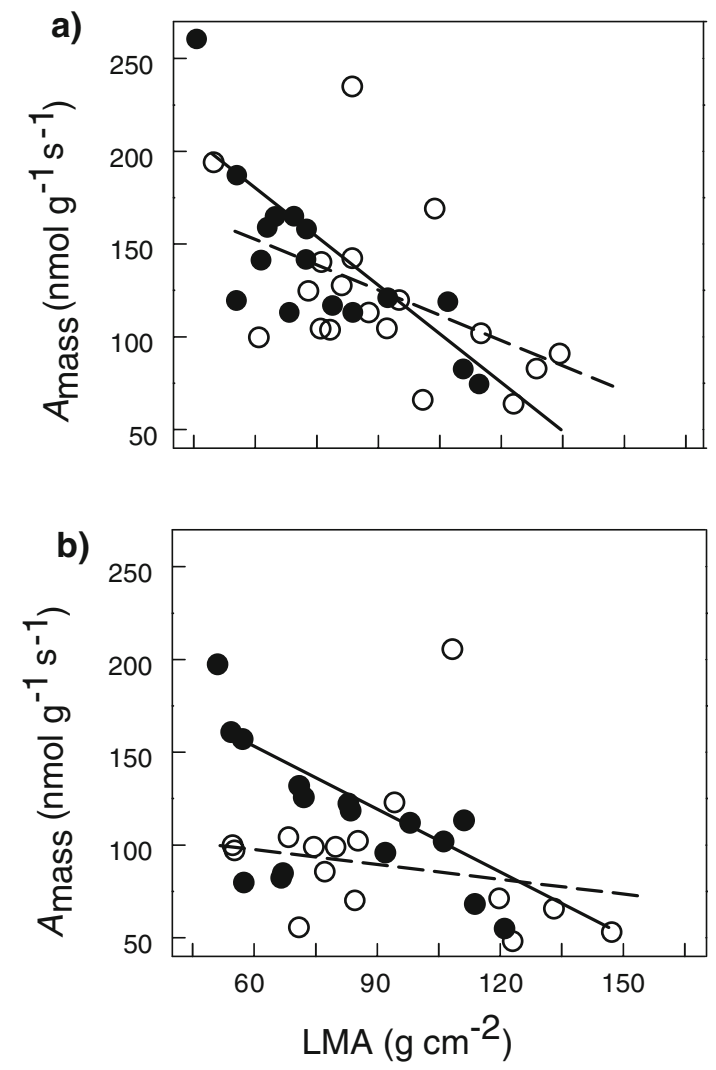

Fig. 3 Relationships between LMA and photosynthetic rates $\left(A_{\text {mass }}\right)$ of lianas (black circles, straight lines) and trees (open circles, broken lines) in wet (a) and dry (b) seasons. Significant correlations were found during the wet season for both lianas and trees: liana $A_{\text {mass }}=-1.65 \mathrm{LMA}+264.7, r^{2}=0.59, P<0.001$; tree $A_{\text {mass }}=-0.93$ $\mathrm{LMA}+205.2, r^{2}=0.24, P=0.039$. During the dry season, however, this relationship was significant for lianas $\left(A_{\text {mass }}=-0.98\right.$ LMA $\left.+192.2, r^{2}=0.37, P=0.013\right)$, but not for trees $\left(A_{\text {mass }}=-0.27\right.$ LMA $\left.+111.2, r^{2}=0.24, P=0.066\right)$ 

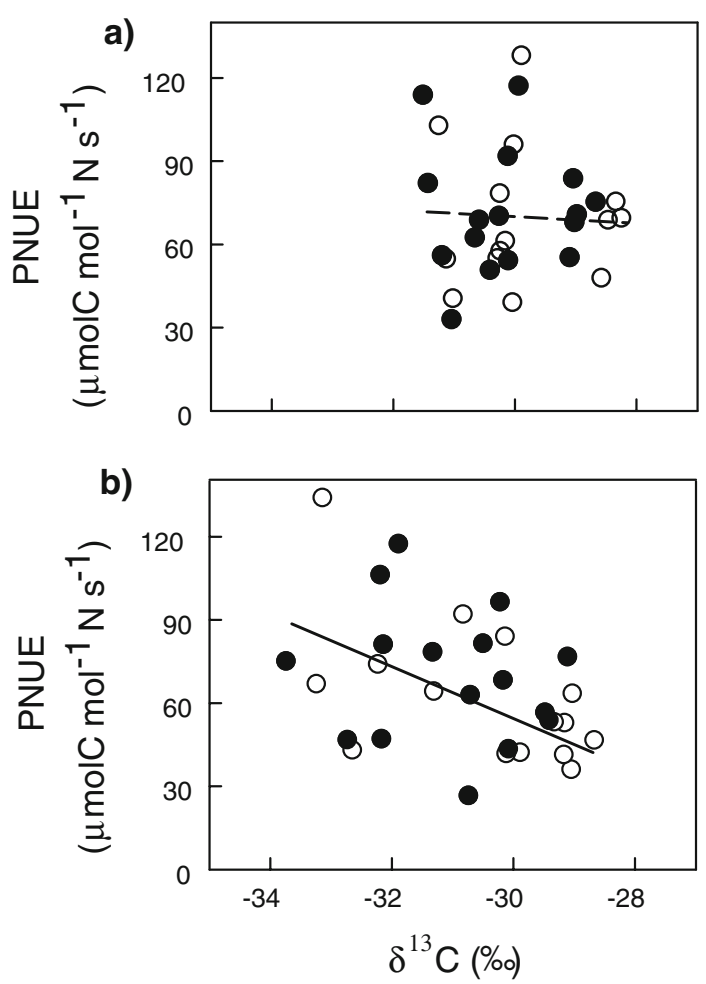

Fig. 4 Relationships between carbon isotope ratio $\left(\delta^{13} \mathrm{C}\right)$ and photosynthetic N-use efficiency (PNUE) for lianas (a) and trees (b) in the wet (black circles) and dry season (open circles). Significant correlations during both wet and dry seasons were found for trees $\left(r^{2}=0.16\right.$, $P=0.024)$, but not for lianas $\left(r^{2}=0.01, P>0.05\right)$

Swaine and Grace 2007; DeWalt et al., unpublished). While $A_{\text {area }}, A_{\text {mass }}, N_{\text {mass }}$, and $P_{\text {mass }}$ for lianas and trees in this study were within a wide range of values consistent with other studies (e.g., Reich et al. 1997; Wright et al. 2004a, b), lianas exhibited less of a decrease in these variables during seasonal drought (Fig. 2). The relatively high photosynthetic capacity of lianas over the dry season may enable them to fix more carbon over this period, and thus have more available carbon to allocate to growth and reproduction. Indeed, in the seasonal moist forest of BCI, lianas grew proportionally more than trees during the dry season compared to the wet season (Schnitzer 2005). Zotz and Winter (1996) reported constant photosynthetic rates for the liana Uncaria tomentosa between wet and dry seasons on BCI, suggesting that this liana did not suffer from seasonal drought.

Our findings that lianas had higher WUE than trees, as indicated by the significantly higher $\delta^{13} \mathrm{C}$ values in both seasons (Fig. 2), are consistent with findings of Foster and Brooks (2005) and Domingues et al. (2007). In general, high leaf-level WUE is thought to be the result of lower water availability (Lambers et al. 1998). The high specific hydraulic conductivity of liana stems (Tyree and Ewers 1996; Andrade et al. 2005), however, may lead to high stomatal conductance and therefore sustained higher transpiration rates (Restom and Nepstad 2001). Santiago and Wright (2007) suggested that the high sap flow capacity of lianas may be balanced by their relatively high leaf area (Putz 1983; Gerwing and Farias 2000), reducing the amount of water supplied to each leaf and thus increasing the need for greater leaf-level WUE. In addition, lianas typically have a greater ratio of leaf area per cross-sectional area of vascular tissue than do trees (Putz 1983). During periods of high evaporative demand, such allometry might place lianas at a higher risk of xylem embolism (Hacke et al. 2006), and thus high WUE may be a necessary wateruse strategy of lianas. Our findings do not imply that lianas will eventually displace trees in highly seasonal tropical forests; rather, they support the hypothesis that lianas abundance is controlled, to a large extent, by mean annual rainfall and seasonality because lianas compete better in forests with these attributes (Schnitzer 2005).

Are lianas superior to trees in resource capture during seasonal drought?

Collectively, our data suggest that lianas and trees differ mostly during the dry season, when lianas become more efficient at capturing resources. We found that lianas and trees were not significantly different in $A_{\text {area }}, N_{\text {mass }}, P_{\text {mass }}$ and PNUE during the wet season, but that the differences in these traits became apparent during the dry season. Our results differ from studies reporting that lianas and trees had similar photosynthetic capacity (Castellanos 1991; Zotz and Winter 1996), or that $A_{\text {area }}$ was lower for lianas than for trees (Santiago and Wright 2007). The high levels of $\delta^{13} \mathrm{C}$ and PNUE during the dry season indicate that lianas have high water- and nitrogen-use efficiency, suggesting that they capture resources more efficiently than trees, which may be particularly important for dry season growth.

The steep tradeoff between $A_{\text {mass }}$ and LMA (Fig. 3) indicates that lianas can attain relatively high carbon assimilation with low leaf construction expenses compared to trees, particularly during the dry season (sensu Field and Mooney 1986; Poorter and Villar 1998). The metabolic efficiency of leaves, however, as measured by the variance of $A_{\text {mass }}$ across all ranges of $R_{\mathrm{d} \text { mass }}$, did not differ between lianas and trees. The Car/Chl ratio for lianas and trees were also similar, indicating that in the high-light canopy conditions lianas and trees have similar strategies for light harvesting and the ability to dissipate excessive light energy via xanthophylls (Demmig-Adams and Adams 1992). Therefore, the differences between lianas and trees appear to lie in the assimilation rate per leaf structural investment (LMA) and the $A / C h l$ ratio: lianas have higher carbon gain per unit leaf area and more photosynthesis per unit chlorophyll. The high $N_{\text {mass }}$ and low LMA, which are consistent 
with previous studies (Kazda and Salzer 2000; Salzer et al. 2006), suggest a higher leaf turnover and a higher decomposition rate (Diaz et al. 2004). Differences between lianas and trees in photosynthetic efficiency over time and leaf life span also affect whole-plant carbon fixation per structural investment, and should be examined to verify whether the conclusions of our short-term study scales temporally and at the whole-plant level. Differences in leaf traits between lianas and trees are likely to have important implications for nutrient cycling in tropical forests if lianas increase substantially in abundance (e.g., Phillips et al. 2002; Wright et al. 2004a, b).

Ecological significance of trade-offs between water-use efficiency and nitrogen efficiency

Prolonged drought restricts the mobility of $\mathrm{N}$ through dehydrated soil and thus co-limitation of water and $\mathrm{N}$ may be common in seasonal forests. During periods of low water availability, stomata generally close, leading to reduced water loss and thus higher WUE. Typically, however, lower internal leaf $\mathrm{CO}_{2}$ concentrations result in decreased photosynthesis; while $\mathrm{N}$ remains constant, resulting in lower PNUE and a trade-off between WUE and PNUE in $\mathrm{C}_{3}$ plants (Field and Mooney 1986). In our study, we found a significant WUE-PNUE trade-off for trees, but not for lianas (Fig. 4). Trees achieved higher PNUE at the expense of decreasing WUE, whereas lianas could simultaneously maintain relative higher WUE and PNUE (Figs. 2, 4). The differences in the trade-off between PNUE and WUE may partially explain the higher rates of photosynthesis in lianas during periods of drought. Alternatively, the lack of a negative WUE-PNUE trade-off for lianas may be explained by the relatively narrow $\delta^{13} \mathrm{C}$ range compared to trees, which may have limited our ability to detect this tradeoff (see also Foster and Brooks 2005; Domingues et al. 2007).

In conclusion, our findings support the dry season growth advantage hypothesis for lianas, which may help explain the peak in liana abundance in the seasonal tropical forests. Unique root, stem, and leaf-level characteristics appear to allow lianas to achieve relatively high rates of carbon gain per leaf mass, area, and structure cost, as well as high resource use efficiency (water and nitrogen) during seasonal drought. Differences in these physiological attributes may explain the competitive advantage of lianas over trees during seasonal drought.

Acknowledgments We thank Chen YaJun and three undergraduate students from Simao Normal College for help with the field work, and S. Mangan, J. Mascaro, L. Poorter, H. Qinming, M. Tobin, and A. Wright for constructive comments. Liu WenJie kindly provided meteorological data from the Ecological Monitoring Station in XTBG. We also thank Li LeYi for carbon isotope analyses, Fu Yun for nutrient analyses, and Wen Bin for species identification. This work was supported financially by a grant (NSFC-30500065) from the National Science Foundation in China, and by a sandwich-PhD grant from Wageningen University. The experiments conducted in this study comply with the current laws of China.

Open Access This article is distributed under the terms of the Creative Commons Attribution Noncommercial License which permits any noncommercial use, distribution, and reproduction in any medium, provided the original author(s) and source are credited.

\section{References}

Andrade JL, Meinzer FC, Goldstein G, Schnitzer SA (2005) Water uptake and transport in lianas and co-occurring trees of a seasonally dry tropical forest. Trees 19:282-289

Avalos G, Mulkey SS (1999) Photosynthetic acclimation of the liana Stigmaphyllon lindenianum to light changes in a tropical dry forest canopy. Oecologia 120:475-484

Bongers F, Poorter L, Van Rompaey RSAR, Parren MPE (1999) Distribution of twelve moist forest canopy tree species in Liberia and Cote d'Ivoire: response curves to a climatic gradient. J Veg Sci 10:371-382

Borchert R (1998) Responses of tropical trees to rainfall seasonality and its long-term changes. Clim Chang 39:381-393

Cai ZQ, Poorter L, Han Q, Bongers F (2008) Effects of light and nutrients on seedlings of tropical Bauhinia lianas and trees. Tree Physiol 28:1277-1285

Cai ZQ, Schnitzer SA, Chen YJ, Wen B, Bongers F (2009) Liana diversity and abundance in three tropical forests in Xishuangbanna, SW China. J Trop For Sci (in press)

Castellanos A (1991) Photosynthesis and gas exchange of vines. In: Putz FE, Mooney HA (eds) The biology of vines. Cambridge University Press, Cambridge, pp 127-160

Condit R, Hubbell SP, Foster RB (1995) Mortality rates of 205 neotropical tree and shrub species and the impact of severe drought. Ecol Monogr 65:419-439

Demmig-Adams B, Adams WWIII (1992) Photoprotection and other responses of plants to high light stress. Annu Rev Plant Physiol Plant Mol Biol 43:599-626

Diaz S, Hodgson JG, Thompson K et al (2004) The plant traits that drive ecosystems: evidence from three continents. J Veg Sci 15:295-304

Domingues TF, Martinelli LA, Ehleringer JR (2007) Ecophysiological traits of plant functional groups in forest and pasture ecosystems from eastern Amazônia, Brazil. Plant Ecol 193:101-112

Engelbrecht BMJ, Kursar TA, Tyree MT (2005) Drought effects on seedling survival in a tropical moist forest. Trees 19:312-321

Farquhar GD, Richards RA (1984) Isotopic composition of plant carbon correlates with water-use efficiency of wheat genotypes. Aust J Plant Physiol 11:539-552

Field C, Mooney HA (1986) The photosynthesis-nitrogen relationship in wild plants. In: Givnish TJ (ed) On the economy of form and function. Cambridge University Press, Cambridge, pp 25-55

Foster TE, Brooks JR (2005) Functional groups based on leaf physiology: are they spatially and temporally robust? Oecologia 144:337-352

Gentry AH (1982) Patterns of neotropical plant species diversity. In: Hecht MK, Wallace B, Prance GT (eds) Evolutionary biology. Plenum, New York, pp 1-84

Gerwing JJ, Farias DL (2000) Integrating liana abundance and forest stature into an estimate of total above-ground biomass for an eastern Amazonian forest. J Trop Ecol 16:327-336

Granados J, Korner C (2002) In deep shade, elevated $\mathrm{CO}_{2}$ increases the vigour of tropical climbing plants. Glob Chang Biol 8:1109-1117 
Hacke UE, Sperry JS, Wheeler JK, Castro L (2006) Scaling of angiosperm xylem structure with safety and efficiency. Tree Physiol 26:689-701

Holbrook MN, Whitbeck JL, Mooney HA (1995) Drought responses of neotropical dry forest trees. In: Bullock SH, Mooney HA, Medina E (eds) Seasonally dry tropical forests. Cambridge University Press, Cambridge, pp 243-270

Kainer KA, Wadt LHO, Gomes-Silva DAP, Capanu M (2006) Liana loads and their association with Betholletia excelsa fruit and nut production, diameter growth and crown attributes. J Trop Ecol $22: 147-154$

Kalácska M, Calvo-Alvarado JC, Sánchez-Azofeifa GA (2005) Calibration and assessment of seasonal changes in leaf area index of a tropical dry forest in different stages of succession. Tree Physiol 25:733-744

Kazda M, Salzer J (2000) Leaves of lianas and self-supporting plants differ in mass per unit area and in nitrogen content. Plant Biol 2:268-271

Kursar TA, Coley PD (1991) Nitrogen content and expansion rate of young leaves of rain forest species: implications for herbivory. Biotropica 23:141-150

Lambers H, Chapin FSIII, Pons TL (1998) Plant physiological ecology. Springer, New York

Li YH, Pei SJ, Xu ZF (1996) List of plants in Xishuangbanna. Yunnan National Press, Kunming

Lichtenthaler HK, Wellburn AR (1983) Determinations of total carotenoids and chlorophylls a and $\mathrm{b}$ leaf extracts in different solvents. Biochem Soc Trans 11:591-592

Mohan JE, Ziska LH, Schlesinger WH et al (2006) Biomass and toxicity responses of poison ivy (Toxicodendron radicans) to elevated atmospheric $\mathrm{CO}_{2}$. Proc Natl Acad Sci USA 103:9086-9089

Opler PA, Baker HG, Frankie GW (1991) Seasonality of climbers: a review and example from Costa Rican dry forest. In: Putz FE, Mooney HA (eds) The biology of vines. Cambridge University Press, Cambridge, pp 377-391

Phillips OL, Vásquez MR, Arroyo L et al (2002) Increasing dominance of large lianas in Amazonian forests. Nature 418:770-774

Poorter L, Bongers F (2006) Leaf traits are good predictors of plant performance across 53 rain forest species. Ecology 87:17331743

Poorter H, Villar R (1998) The fate of acquired carbon in plants: chemical composition and construction costs. In: Bazzaz FA, Grace $\mathbf{J}$ (eds) Plant resource allocation. Academic, New York, pp 39-72

Putz FE (1983) Liana biomass and leaf area of a "tierra firme" forest in the Rio Negro basin, Venezuela. Biotropica 15:185-189

Putz FE (1984) The natural history of lianas on Barro Colorado Island, Panama. Ecology 65:1713-1724

Putz FE, Mooney HA (1991) The biology of vines. Cambridge University Press, Cambridge

Putz FE, Windsor DM (1987) Liana phenology on Barro Colorado Island, Panama. Biotropica 19:334-341

Reich PB, Walters MB, Ellsworth DS (1997) From tropics to tundra: global convergence in plant functioning. Proc Natl Acad Sci USA 94:13730-13734

Restom TG, Nepstad DC (2001) Contribution of vines to the evapotranspiration of a secondary forest in eastern Amazon. Plant Soil 236:155-163

Restom TG, Nepstad DC (2004) Seedling growth dynamics of a deeply rooting liana in a secondary forest in eastern Amazonia. For Ecol Manag 190:109-118
Salzer J, Matezki S, Kazda M (2006) Nutritional differences and leaf acclimation of climbing plants and the associated vegetation in different types of an Andean montane rainforest. Oecologia 147:417-425

Santiago LS, Wright SJ (2007) Leaf functional traits of tropical forest plants in relation to growth form. Funct Ecol 21:19-27

Schnitzer SA (2005) A mechanistic explanation for global patterns of liana abundance and distribution. Am Nat 166:262-276

Schnitzer SA, Bongers F (2002) The ecology of lianas and their role in forests. Trends Ecol Evol 17:223-230

Schnitzer SA, Dalling JW, Carson W (2000) The importance of lianas on tree regeneration in tropical forest canopy gaps: evidence for an alternative pathway of gap-phase regeneration. J Ecol 88:655666

Schnitzer SA, Parren MPE, Bongers F (2004) Recruitment of lianas into logging gaps and the effects of pre-harvesting climber cutting. For Ecol Manag 190:87-98

Schnitzer SA, Kuzee ME, Bongers F (2005) Disentangling above- and below-ground competition between lianas and trees in a tropical forest. J Ecol 93:1115-1125

Slot M, Poorter L (2007) Diversity of tropical tree seedling responses to drought. Biotropica 39:683-690

Swaine MD (1996) Rainfall and soil fertility as factors limiting forest species distributions in Ghana. J Ecol 84:419-428

Swaine MD, Grace J (2007) Lianas may be favoured by low rainfall: evidence from Ghana. Plant Ecol 192:271-276

Tyree MT, Ewers FW (1996) Hydraulic architecture of woody plants. In: Mulkey SS, Chazdon RL, Smith AP (eds) Tropical forest plant ecophysiology. Chapman \& Hall, New York, pp 217-243

van der Heijden GMF, Healey JR, Phillips OL (2008) Infestation of trees by lianas in a tropical forest in Amazonian Peru. J Veg Sci 19:747-756

Veenendaal EM, Swaine MD, Agyeman VK et al (1995) Differences in plant and soil water relations in and around a forest gap in West Africa during the dry season may influence seedling establishment and survival. J Ecol 83:83-90

Walsh RPD, Newbery DM (1999) The ecoclimatology of Danum, Sabah, in the context of the world's rainforest regions, with particular reference to dry periods and their impact. Philos Trans $\mathrm{R}$ Soc Lond 54:1869-1883

Wright IJ, Reich PB, Westoby M et al (2004a) The world-wide leaf economics spectrum. Nature 428:821-827

Wright SJ, Calderon O, Hernandez A, Paton S (2004b) Are lianas increasing in importance in tropical forests? A 17-year record from Panama. Ecology 85:484-489

Wright SJ, Jaramillo AM, Pavon J, Condit R, Hubbell SP, Foster RB (2005) Reproductive size thresholds in tropical trees: variation among individuals, species and forests. J Trop Ecol 21:307-3115

Xu ZF (1994) Ficus: a key species in the forest ecosystem in the tropical rainforest in south Yunnan, China. Chin Biodivers 2:21-23

Zhu H, Cao M, Hu HB (2006) Geological history, flora, and vegetation of Xishuangbanna, southern Yunnan, China. Biotropica 38:310 317

Zotz G, Winter K (1996) Diel patterns of $\mathrm{CO}_{2}$ exchange in rainforest canopy plants. In: Mulkey SS, Chazdon RL, Smith AP (eds) Tropical forest plant ecophysiology. Chapman \& Hall, New York, pp 89-113

Zotz G, Cueni N, Körner C (2006) In situ growth stimulation of a temperate zone liana (Hedera helix) in elevated $\mathrm{CO}_{2}$. Funct Ecol 20:763-769 